\title{
SEXUALIDADE NA LONGEVIDADE E SUA SIGNIFICAÇÃO EM QUALIDADE DE VIDA
}

\author{
Francisco Fabrício Firmino de Oliveira'; Kay Francis Leal Vieira ${ }^{2}$
}

\author{
SEXUALITY IN LONGEVITY AND ITS SIGNIFICANCE IN QUALITY OF LIFE
}

\begin{abstract}
Resumo: $O$ artigo consiste numa revisão da literatura sobre a sexualidade na longevidade e sua contribuição para a qualidade de vida da pessoa idosa. Inicialmente, trazemos um breve resumo sobre sexualidade na longevidade com seus aspectos positivos que perpassam gerações trazendo qualidade de vida, saúde e bem estar e resignificando a vida dos idosos. Discorremos sobre mitos e verdades no quesito sexualidade na vida dos longevos. Por fim, destacamos as motivações dos idosos para a manutenção de uma vida sexual ativa com suas inovações e adaptações, considerando que apesar do envelhecimento trazer modificações na vida sexual da pessoa idosa é importante ressaltar que as vivências sexuais se mostra essencial para que se envelheça com uma boa qualidade de vida.
\end{abstract}

Palavras-chave: Longevidade. Sexualidade. Qualidade de vida.

Abstract: The article consists of a review of the literature on sexuality in longevity and its contribution to the quality of life of the elderly person. Initially, we bring a brief summary about sexuality in longevity with its positive aspects that span generations bringing quality of life, health and well-being and resignifying the life of the elderly. We talk about myths and truths in the question of sexuality in the lives of the long-lived. Finally, we highlight the motivations of the elderly for the maintenance of an active sexual life with their innovations and adaptations, considering that despite the aging bring changes in the sexual life of the elderly person, it is important to emphasize that sexual experiences are essential for aging with a good quality of life.

Keywords: Longevity. Sexuality. Quality of life.

\section{Introdução}

O crescimento da população idosa é um fenômeno mundial e, no Brasil, as modificações ocorrem de maneira repentina e bastante acelerada. As projeções mais conservadoras indicam que, em 2020, o Brasil será o sexto país do mundo em quantidade de população idosa, com um contingente superior a 30 milhões de pessoas segundo a Organização Mundial da Saúde (OMS) em 2010.

Esse aumento expressivo de pessoas idosas exige a necessidade de políticas públicas que venham atender adequadamente as perspectivas dessa demanda. Como - Brasil não se projetou para atender as necessidades dessa população, o envelhecimento é tratado como um "problema" e não como uma conquista, sendo as pessoas idosas vistas como um encargo para a família, para - Estado e para a sociedade (SIQUEIRA; BOTELHO; COELHO, 2002).

Sendo o Estado, em todos os seus níveis, o principal responsável pela implementação de medidas relacionadas ao processo do envelhecimento e ao bem estar da pessoa idosa, torna-se relevante principalmente nesse momento em que se visualiza um aumento expressivo de pessoas envelhecendo na sociedade brasileira, que a população se aproprie de concepções mais positivas sobre a velhice, desconstruindo visões distorcidas e estereotipadas sobre essa fase do desenvolvimento humano, principalmente no tocante à sexualidade.

\footnotetext{
' Psicólogo pelo Centro Universitário de João Pessoa (UNIPÊ), em 20I3. Especialista em Gestão com Pessoas e Psicologia Organizacional pela UNIPÊ, em 2015. Pós - Graduado em Envelhecimento - Geriatria Prática no Hospital da Universidade de Coimbra - Portugal, em 2016. Pós Graduado em Gerontologia pelas Faculdades Integradas de Patos (-FIP), em 2016/2017. Mestrando em Ciências da Saúde pelo Centro Integrado de Ensino (-UNICORP), em 2017/20I8/2019. E-mail: secretaria@unicorpmais.com.br.

2 Psicóloga. Doutora em Psicologia Social pela Universidade Federal da Paraíba (-UFPB). Professora da graduação e pós graduação das Faculdades Nova Esperança e do Centro Universitário de João Pessoa (UNIPE). Docente e pesquisadora do Curso de Mestrado Profissional em Saúde da Família da Faculdade Nova Esperança (-FACENE). Coordenadora dos Cursos de Pós Graduação em Avaliação Psicológica do Centro Universitário de João Pessoa (-UNIPÊ). E-mail: pos@unipe.br.
} 
Segundo Silva (2003), o senso comum tem associado a velhice à dependência, e a sexualidade nesta faixa etária é relacionada à perda. As abordagens médica, biológica e psicológica, na maioria das vezes, tendem a confirmar o envelhecimento como tempo de declínio e decadência. Assim, a velhice tem sido pensada quase sempre como um processo degenerativo, oposto a qualquer progresso ou desenvolvimento, após o limite socialmente definido como fim do período produtivo.

Nesse contexto, verifica-se uma conduta paradoxal da sociedade brasileira: enquanto a população envelhece abruptamente, observa-se uma não aceitação das práticas amorosas e manifestações sexuais em pessoas idosas. A cultura do povo brasileiro influencia para que a pessoa idosa tenha uma percepção de valor ativa de sua sexualidade, isso porque as pessoas de mais idade, sempre foram imaginadas como assexuadas, desprovidas de qualquer manifestação sexual.

As vivências da sexualidade, afetividade e intimidade que estão genuinamente imbricadas, são negadas nas sociedades ocidentais; assim esses elementos fundamentais para uma boa vida são abdicados ou substituídos por outros, contribuindo para que a pessoa idosa não vivencie a singularidade desses sentimentos (SIQUEIRA; BOTELHO; COELHO, 2002).

\section{A sexualidade na longevidade}

A sexualidade é entendida nos dias atuais em um sentido amplo, que não apenas envolve o fisiológico, sendo compreendida como um elemento que dá sentido e significado à existência humana (MARTINEZ FERNANDEZ; SANTOS PANIAGUA, 2007). Corresponde a uma função vital do ser humano, na qual intervêm múltiplos fatores de ordem biológica, psicológica, social e cultural. Portanto, a sexualidade na velhice, assim como nas demais faixas etárias, não se refere somente à prática sexual em si, mas à troca de afeto, carinho, companheirismo, cumplicidade, cuidados um com o outro, segurança e conforto. Vasconcellos e colaboradores (2004) afirmam que a relação sexual entre pessoas idosas está intrinsecamente ligada ao processo de intimidade que há entre o casal.

Dificilmente a intimidade e o sexo acontecem de forma separada, uma se torna o complemento da outra, principalmente nessa idade. Socialmente, tem-se considerado a pessoa idosa como assexuada, desprovida de desejos e de vida sexual, como se os anos the trouxessem uma inapetência neste aspecto vital do desenvolvimento humano (MURILLO GONZALEZ; RAPOZO BRENES, 2007). Entretanto, atualmente, sabe-se que as vivências sexuais são uma realidade cotidiana para os idosos, proporcionando satisfação física e mental. De acordo com Silva (2003), não existem razões fisiológicas que impeçam as pessoas idosas, em condições satisfatórias de saúde, de apresentarem uma vida sexual ativa.

A sexualidade na velhice pode ser vivenciada pelos idosos das mais diversas maneiras, mas sempre acontece como uma forma de expressão verdadeira de carinho. A esse respeito, Vasconcellos e colaboradores (2004), expressam que tais sentimentos não se perdem com o tempo, haja vista que o amor e o sexo podem significar muitas coisas para as pessoas no processo de envelhecimento como: oportunidade de expressar afeto, admiração e amor pelo outro; conhecimento de seu próprio corpo e suas limitações; uma forte percepção de si mesmo.

Contudo, se a maturidade trouxer o afeto, a paixão, o namoro, o amor, o sexo, a cumplicidade, o companheirismo, dentre outros, a pessoa idosa poderá ter uma satisfatória vida afetiva. Dessa forma, conforme expressam Almeida e Lourenço (2007), se o idoso se permitir tais vivências pode-se supor que ele terá um envelhecimento positivo, ao contrário, daqueles que somente darão vazão a um saudosismo passivo, ou ainda, a qualquer outro tipo de posicionamento imobilizador e negativo.

Diante dessa realidade, observa-se, portanto, que em algumas sociedades o significado da velhice está diretamente ligado a uma concepção negativa, em que a pessoa idosa é percebida literalmente, como um ser social estéril. Esse negativismo cultural também reflete na sexualidade dos longevos.

A dificuldade de reconhecer a sexualidade na pessoa idosa, segundo Rodrigues (2008), baseia-se em vários fatores valorativos originados na interpretação sociocultural que reforça o culto a corpos perfeitos, esculpidos em academias, ao vigor físico e à juventude. Portanto, a sociedade dita às regras, estabelece os limites da sexualidade e demarca as condições e as aceitações. Nesse cenário, Bernardino (20l I) afirma que a prática ao culto jovem e ao consumo de novas imagens e ideias provocam discussões acerca do envelhecimento, carregadas de estereótipos e de segregação. A autora afirma que enfatizar a beleza física e usar o corpo para atrair o outro são práticas comuns do ser humano. Esse comportamento auxiliou na construção social de crenças, mitos e atitudes segregativas voltadas para a velhice, já que as construções sociais externalizam a concepção de que os idosos são incapazes de usufruir das vivências sexuais.

A falta de informação sobre o processo de enveIhecimento e as mudanças ocorridas na sexualidade tem auxiliado na manutenção de preconceitos e, consequentemente, trouxeram muitas estagnações das atividades sexuais das pessoas idosas. Tal fato, inevitavelmente, acarreta prejuízos para a qualidade de vida da pessoa idosa (VIEIRA, 20I2). A pressão social para um bom comportamento é tão forte ao ponto de impedir que os idosos vivam como desejam, nos vários aspectos da sexualidade. 
Portanto, querendo manter o segredo ou por vergonha, os idosos sentem-se incompreendidos ou constrangidos pela impossibilidade de buscar informações mais apuradas ou mesmo uma franca discussão.

A sociedade impõe certos padrões de comportamento, que limitam a sexualidade humana a um período compreendido entre a puberdade e o início da maturidade. Sendo assim, a atividade sexual não é reforçada pela sociedade na velhice. Ao contrário, é punida por meio dos preconceitos. Os idosos são submetidos a essa ideia imposta pela sociedade, e aliados às modificações fisiológicas características do envelhecimento, parecem aceitar a dessexualização como um processo normal da idade (CASTRO; REIS, 2002).

\section{Mitos e verdades da sexualidade na longevidade}

Em nossa cultura há mitos e atitudes preconceituosas relacionadas à sexualidade da pessoa idosa como se fosse atributo somente das pessoas mais jovens. Apesar disso, é necessário ressaltar que na velhice mantém-se a necessidade psicológica de uma vida sexual ativa, não havendo idade correta para que acabem os pensamentos sobre sexo, desejo ou atividade sexual. Assim, a sexualidade humana, não pode ser entendida apenas com o conhecimento da anatomia e da fisiologia sexuais, também se deve levar em conta os aspectos psicológicos e culturais de cada indivíduo, já que a sexualidade não se reduz apenas à prática do ato sexual e à satisfação orgástica, significa uma integração harmoniosa dos aspectos intelectuais e sociais do ser sexuado, enriquecendo sua personalidade, comunicação e amor, conforme Capodieci (2000).

Nesse sentido, o sexo é reconhecido como um aspecto importante da saúde e, se for vivido satisfatoriamente, é fonte de equilíbrio e harmonia para a pessoa idosa, favorecendo uma atitude positiva em relação a si mesmo e aos outros. É nesse contexto que surge a necessidade de uma releitura dessa percepção estereotipada e estigmatizante da sexualidade da pessoa idosa, para construirmos uma concepção mais positiva acerca dessa temática.

A sexualidade na velhice é simples e, ao mesmo tempo, complexa, afinal o corpo envelhece, a anatomia e a fisiologia sexual modificam-se, mas a capacidade de amar continua intacta até o final da vida. As formas de expressar a sexualidade do idoso servem para promover a comunicação, a confiança, o carinho, a partilha e o prazer (ALMEIDA; LOURENÇO, 2007). O idoso, possuindo o conhecimento adequado sobre seu corpo, sobre mudanças físicas ocorridas e tendo informações a respeito de sexualidade, pode alcançar e manter uma atividade sexual satisfatória. Tal justificativa se dá pela importância que os idosos dão ao sexo, que este contribui para seu bem-estar físico e psicológico.

Para Capodieci (2000), com a idade há uma diminuição progressiva da atividade sexual no indivíduo, causada pela intervenção das mudanças fisiológicas normais devidas ao envelhecimento em inter-relação com os fatores psicossociais. $\mathrm{O}$ autor em seu livro descreveu que muitos idosos se sentem mais jovens, que os avanços da medicina facilitaram a obtenção de um desempenho sexual melhor, e que uma grande maioria indicou que o sexo depois dos 60 anos os satisfaz mais do que quando eram mais jovens.

Na idade avançada se ama de maneira mais profunda, consegue-se purificar o amor da paixão que é mais sensual do que genital. Os idosos falam mais facilmente a linguagem do coração com palavras mais sinceras e espontâneas e com silêncios mais carinhosos. Assim, para eles, um olhar ou uma carícia podem valer mais do que muitas declarações de amor (CAPODIECI, 2000, p. 23I)

De maneira geral, entende-se que a sexualidade e a possibilidade de vivenciá-la de maneira prazerosa são exatamente possíveis durante a velhice, embora em alguns casos, devido a algumas limitações físicas, seja necessária alguma adaptação. Entretanto, as necessidades tendem a ser iguais às outras pessoas vivendo a sua etapa de vida, de poder relacionar-se, de expressar o amor, carinho, sem deixar de lado, a vida sexual. É uma continuidade natural do processo de envelhecer.

Conforme Pascual (2002), a idade não elimina a necessidade, 0 desejo, nem a capacidade de desfrutar de um relacionamento sexual. A função sexual nessa idade é normal, porém a continuidade depende das circunstâncias da própria pessoa, das mudanças fisiológicas, dos fatores psicológicos, afetivos, socioculturais, das enfermidades, e outros. $O$ autor destaca também que o sexo é uma oportunidade de expressar carinho, afeto, admiração por alguém, eleva a autoestima e melhora o humor e a qualidade de vida. $O$ fator que mais interfere na sexualidade do idoso é a falta de amor, carinho e compreensão por parte do parceiro, seguido da mídia e das questões relacionadas à saúde

De acordo com Castro e Reis (2002), os padrões de comportamento são criados pela sociedade, que limita a sexualidade a um período compreendido entre a puberdade e o início da maturidade. Portanto, o comportamento sexual não costuma ser reforçado pela sociedade na velhice e, ao contrário, é severamente punido pelo preconceito que permeia essas relações.

Apesar desses mitos culturais, a necessidade psicológica de intimidade, excitação e prazer não desaparecem na velhice, nem há na biologia do envelhecimento qualquer fator que encerre de forma automática a função 
sexual. Contudo, para Almeida e Lourenço (2007), a velhice é uma idade tão frutífera como qualquer outra no que se refere à questão da prática da sexualidade e à vivência do amor. Não há como negar a essas pessoas o direito a uma vida mais prazerosa, já que nessa idade as pessoas se amam de maneira mais profunda, utilizando mais facilmente a linguagem do coração, em que muitas vezes um olhar e uma carícia podem valer mais do que muitas declarações de amor (CAPODIECI, 2000, p. 23I).

\section{Benefícios das vivências sexuais para a qualidade de vida}

O conceito de qualidade de vida está relacionado à autoestima e ao bem-estar pessoal e abrange uma série de aspectos como a capacidade funcional, o nível sócio econômico, o estado emocional, a interação social, a atividade intelectual, o autocuidado, o suporte familiar, o próprio estado de saúde, os valores culturais, éticos e a religiosidade, o estilo de vida, a satisfação com o emprego e/ ou com atividades diárias e o ambiente em que se vive (ORGANIZAÇÃO MUNDIAL DA SAÚDE, 20I0).

Apesar da existência de um consenso acerca da importância da avaliação da qualidade de vida, o mesmo não ocorre com o seu conceito, campo esse repleto de frequentes e significativos debates. Caracteriza-se como um dos conceitos mais discutidos da atualidade, embora não se consiga precisar exatamente o que significa (RIBEIRO; COUTINHO, 20II). A definição de qualidade de vida varia de autor para autor e, além disso, é um conceito subjetivo dependente do nível sociocultural, da faixa etária e das aspirações pessoais do indivíduo (FIGUEIREDO, 20I4).

Atualmente, a qualidade de vida é vista como uma noção eminentemente humana, avaliada mediante o grau de satisfação encontrado nos mais diversos campos da vida humana: familiar, amoroso, social e ambiental. Segundo Cachioni e Falcão (2009), pressupõe a capacidade de efetuar uma síntese cultural de todos os elementos que determinada sociedade considera como seu padrão de conforto e de bem-estar. Dessa forma, o termo abrange muitos significados, que refletem conhecimentos, experiências e valores de indivíduos e coletividades que a ele se reportam, em variadas épocas, espaços e histórias diferentes.

Segundo Tempski (2004), a definição proposta pela OMS é a que melhor traduz a abrangência do construto qualidade de vida, pois a conceitua como a percepção do indivíduo a respeito de sua posição na vida, no contexto cultural e sistema de valores em que vive, e em relação a suas metas, expectativas, padrões e conceitos. Tal percepção é afetada de forma complexa pela saúde física da pessoa, por seu estado psicológico, crenças pessoais, relações sociais e ambientais.
De acordo com Vieira (20I2), a preocupação com a qualidade de vida dos idosos ganhou relevância nas últimas décadas, através do crescimento do número de pessoas com essa faixa etária e a expansão da longevidade. Nessa ótica, ainda de acordo com a autora supracitada, diante do processo inegável de envelhecimento populacional, surge a necessidade de se proporcionar aos idosos não só uma sobrevida maior, mas, sobretudo, com uma melhor qualidade, sendo as vivências sexuais apontadas como um dos fatores que mais contribuem positivamente nesse sentido.

Na percepção de Capodieci (2000) a geração atual de idosos não teve orientação sexual ou é fruto de uma educação muito severa. Os pais desses idosos de hoje, tinham por orientação sexual os conceitos e preconceitos repressores, herdados de outra geração mais repressora ainda, e para muitos, o sexo era para ser praticado na escuridão com o intuito de procriação.

Durante a velhice não se deixa de amar, mas reinventam-se formas amorosas. É de extrema importância poder pensar que a partir da redescoberta do sexo e do amor, enfim, de sua sexualidade, as pessoas idosas reconquistam o lugar vital de homem e mulher e não mais o de "velho", que tem como futuro o fim da vida. Novamente, é na relação com o outro que está à importância da redescoberta do desejo de viver. Capodieci (2000) em seus em estudos afirma que as fantasias sexuais, sob forma de sonhos, ou sublimadas em expressões artísticas, são retomadas na relação direta de namoro ou na relação com os familiares, netos, bisnetos e amigos, independentemente da idade ou da limitação física da velhice.

Vários elementos são apontados como determinantes ou indicadores de bem-estar na velhice: longevidade; saúde biológica; saúde mental; satisfação; controle cognitivo; competência social; produtividade; atividade; eficácia cognitiva; status social; renda; continuidade de papéis familiares e ocupacionais, e continuidade de relações informais em grupos primários (principalmente rede de amigos). Se além desses elementos, a maturidade ainda trouxer o afeto, a paixão, o namoro, o amor, o sexo, a cumplicidade, o companheirismo, dentre outros, o idoso pode estar certo de que, poderá ter uma satisfatória vida afetiva onde as possibilidades de relacionamento amoroso nesta etapa da vida, apesar de algumas vezes serem difíceis, são mais viáveis do que muitas pessoas imaginam (ALMEIDA; LOURENÇO, 2007).

As transformações e adaptações das atividades sexuais nos longevos vêm com mudanças nas relações conforme os modelos surgidos na contemporaneidade e que de alguma forma afetam suas vivências e experiências passadas, de modo diferenciado entre homens e mulheres, em diversas fases de suas vidas. Segundo Michel Bozon (2004), a prática sexual não se encontra mais concentrada na idade adulta, haja vista que as pessoas 
se iniciam sexualmente cada vez mais cedo e prosseguem sua vida sexual na velhice.

O prolongamento da vida sexual até idades mais avançadas está relacionado à ampliação da expectativa de vida, à difusão do ideal de juventude, e à ampliação das esferas de autonomia individual, que fazem recuar aos poucos os preconceitos tradicionais contra a sexualidade na velhice.

Embora afetando homens e mulheres, essas mudanças são mais aguçadas para estas últimas, uma vez que a atividade sexual feminina costumava ficar encerrada no casamento, sendo frequentemente circunscrita à idade reprodutiva. Não estando mais atrelada à condição conjugal, a prática sexual feminina se estende agora velhice adentro, tanto entre mulheres que nunca casaram, como entre divorciadas e mulheres viúvas UCHÔA (2003).

Segundo Perry e Potter (2005), existem muitos mitos comuns e concepções errôneas sobre sexo e enveIhecimento, como pensar que sexo não tem importância na velhice, que os últimos anos deveriam ser assexuados, que é anormal os idosos terem interesse por sexo e normal que os homens idosos procurem por mulheres mais jovens. Esses mitos prejudicam, sobretudo, as mulheres idosas, que, frequentemente, se sentem incapazes de manter um bom relacionamento sexual.

De acordo com Fraiman (1994), muitas mulheres reprimidas sexualmente, com o passar dos anos, na medida em que ganham experiências sexuais, mais confiança em si mesmo e no parceiro, podem usufruir maior prazer na relação sexual do que quando eram jovens. As atividades sexuais, segundo Beauvoir (1990), têm uma pluralidade de fins. As gratificações que um indivíduo tira de suas atividades sexuais são de grande diversidade e de grande riqueza.

Lopes e Cabral (2004) afirmam em seus estudos que o aumento dos distúrbios sexuais nessa etapa da vida se deve, fisiologicamente, à diminuição na produção hormonal, ao desgaste da condição social, a manifestações depressivas e a problemas na relação conjugal. Tais mudanças que ocorrem na vida sexual durante $o$ amadurecimento e o envelhecimento são em muitos aspectos positivas. Isso não quer dizer que a vida sexual de uma pessoa idosa seja melhor do que a de uma pessoa jovem, mas significa que a vida sexual deste idoso é melhor em muitos aspectos do que quando ele era jovem. Essa melhora ocorre principalmente com as mulheres, pois as idosas de hoje, que nasceram há mais de 60 anos, foram criadas numa cultura cheia de tabus e proibições no tocante aos assuntos da sexualidade.

De acordo com Almeida e Lourenço (2007, p. I55) "é comum para as pessoas, em algum momento da vida, buscar um parceiro com quem possam compartilhar afetividade, alegria, prazer, companheirismo, sexo, dentre outros aspectos". Pelo desejo ele pode reavivar as cores de seus anos passados e viris. Porém, esse desejo só se encontra em idosos que atribuíram ao longo da vida um valor positivo a atividade sexual. Pessoas que repugnavam as atividades sexuais, utilizam a desculpa de estar velho para "poder" abandonar a vida sexual ativa. Enfim, segundo Beauvoir (1990) a vida sexual prolonga-se tanto mais, quanto mais rica e mais feliz tiver sido.

O envelhecimento é uma experiência heterogênea, isto é, pode ocorrer de modo diferente para indivíduos que vivem em contextos históricos e sociais distintos. Essa diferenciação depende da influência de circunstâncias histórico-culturais, de fatores intelectuais e de personalidade, dos hábitos e atividades físicas ao longo da vida e da incidência de patologias durante o envelhecimento normal.

Para Salgado (2005) a velhice é analisada como uma etapa da vida na qual, em decorrência da alta idade cronológica, ocorrem modificações biopsicossociais que afetam a relação do indivíduo com o meio. A experiência das pessoas que envelhecem não pode ser compreendida, a menos que percebamos que o processo de enveIhecimento produz uma mudança fundamental na posição de uma pessoa na sociedade e, portanto, em todas as suas relações com os outros (ELIAS, 200I). E graças às mudanças na qualidade de vida das pessoas, podemos dizer que a velhice não é o fim, mas o começo de uma nova etapa.

Qualidade de vida na velhice tem relação direta com bem estar percebido. A velhice não se reduz a um simples fenômeno biológico, é um fenômeno social. A idade, em última análise, mede-se não tanto pelo número de anos que se tem, mas como a pessoa se sente, como vive, como se relaciona com a vida e com os outros. Portanto, o sexo na velhice é emocional, envolve tanto a parte física como a comunicação, é aprendido e menos instintivo, possibilita novas experiências criativas e exige sensibilidade, como em qualquer fase da vida.

\section{Considerações finais}

A velhice, tal como a infância, a juventude e a vida adulta é percebida como etapas de transformações, tanto na dimensão física como biológica, emocional e sexual, onde a vivência de cada um se dá de maneira homogênea. A forma como cada pessoa envelhece está diretamente relacionada às condições subjetivas de cada um e as questões socioculturais que a pessoa se encontra inserida.

Mesmo sabendo que o envelhecimento traz modificações na vida sexual da pessoa idosa, é importante ressaltar que a sexualidade se mostra essencial para que as pessoas que envelhecem tenham uma boa qualidade de vida. Verifica-se ser de fundamental importância a compreensão acerca da forma como esta demanda populacional percebe e vivencia, tendo em vista que as 
representações sociais influenciam os comportamentos de uma sociedade.

A sexualidade é um elemento fundamental para uma boa qualidade de vida; é normal pessoas mais velhas continuarem tendo desejos, mas, muitas vezes, os reprimem porque a sociedade impõe certos moralismos. Observa-se, empiricamente que as questões relacionadas à sexualidade são discutidas abertamente quando se trata de adolescentes e de adultos. Mas é uma questão pouco considerada na terceira idade e, muitas vezes, negada.

A sexualidade e o amor não possuem idade, estando presentes desde o nascimento até a morte e contribuem para uma maior satisfação com a vida em geral. Compreende-se também que as expressões de afeto, carinho, sensação de aconchego, capacidade de amar e o desejo por intimidade não acabam em nenhuma idade, podendo ser realizados por toda a vida e sua manifestação é vital para o desenvolvimento das pessoas de mais idade, proporcionando-Ihes autoestima e realização pessoal. Conforme destacado, amor, afeto, intimidade e sexo são elementos de valor fundamental na tessitura da vida.

Conclui-se que negar a sexualidade das pessoas idosas é privá-las de direitos. Torna-se assim imprescindível romper com mitos, tabus e preconceitos, no que tange à sexualidade das pessoas na velhice, para que estas possam exercê-la em busca de uma velhice com mais dignidade. É fundamental que os profissionais de saúde colaborem para desconstruir essa concepção estigmatizante sobre a sexualidade da pessoa que envelhece, pois, a sexualidade é uma parte importante da existência humana em qualquer etapa da vida. Em qualquer idade é sempre tempo de viver, de expressar e de amar.

\section{Referências}

ALMEIDA, T.; LOURENÇO, M. L.

Envelhecimento, amor e sexualidade: utopia ou realidade? Revista Brasileira de Geriatria Gerontologia, Rio de Janeiro, v. 10, n. I, p. I01III3, 2007.

BEAVOUIR, S. A velhice. Rio de Janeiro: Nova Fronteira, 1990.

BERNARDINO, E. A sexualidade na terceira idade: o discurso social do suposto corpo assexuado. 20II. 4I f. Trabalho de Conclusão de Curso (Graduação) - Curso de Psicologia, Faculdade do Vale do Ipojuca, Caruaru, 20II. Disponível em: <http://repositorio.favip.edu. br:8080/bitstream/I 23456789/459/I/TCC_IIEdjane.pdf $>$. Acesso em: 04 jan. 2017.

BOZON, M. A nova normatividade das condutas sexuais ou a dificuldade de dar coerência às experiências íntimas. In: HEILBORN, M. L. (Org.). Família e sexualidade. Rio de Janeiro: FGV, 2004b. p. II9-150.

\section{CACHIONI, M.; FALCÃO, D. V. S. Velhice} e educação: possibilidades e benefícios para a qualidade de vida. In: FALCÃO, D. V. S.; ARAÚJO, L. F. (Ed.). Psicologia do envelhecimento: relações sociais, bem-estar subjetivo e atuação profissional em contextos diferenciados. Campinas, SP: Alínea, 2009. p. 175-194.

CASTRO, N. M. S.; REIS, C A C. Sexualidade na terceira idade: não posso, não quero ou não devo. O mito da dessexualização das idosas e a influência da estereotipia negativa as mesmas e suas consequências na vida afetiva e sexual. Revista Iniciação Científica Newton Paiva, Belo Horizonte, v. 3, 2002.

CAPODIECI, S. A idade dos sentimentos: amor e sexualidade após os 60 anos. Bauru: Edusc, 2000.

ELIAS, N. A solidão dos moribundos. Rio de Janeiro: Jorge Zahar, 200I.

\section{MARTINEZ FERNANDEZ, L.; SANTOS}

PANIAGUA, C. La sexualidad em la persona adulta mayor. In: MURILLO GONZALEZ, A. C.; RAPOZO BRENES, M. (Ed.). Envejece $L a$ sexualidade? Buenos Aires: Espacio Editorial, 2007. p. 15-35.

FIGUEIREDO, F. F. Q. B. O envelhecimento humano: aprender a viver com a idade. Lisboa: Edições Vieira da Silva, 2014.

FRAIMAN, A. P. Sexo e afeto na terceira idade. São Paulo: Gente, 1994.

\section{MURILLO GONZALEZ, A. C.; RAPOZO}

BRENES, M. Modificaciones en la sexualidad ocasionadas por el proceso de envejecimiento. In: MURILLO GONZALEZ, A. C.; RAPOZO BRENES, M. (Ed.). Envejece La sexualidade? Buenos Aires: Espacio Editorial, 2007. p. 15-35.

LOPES, G.; CABRAL, R. Sinais e sintomas em transtornos sexuais. In: GUIMARÃES, R. M.; CUNHA, U. G. V. Sinais e sintomas em geriatria. São Paulo: Atheneu, 2004. p. 229-235.

ORGANIZAÇÃO MUNDIAL DE SAÚDE. O papel da atividade física no envelhecimento saudável. Florianópolis, 2010. 
PASCUAL, C. P. A sexualidade do idoso vista com novo olhar. São Paulo: Loyola, 2002.

PERRY, A. G.; POTTER, P. A. Grande tratado de enfermagem prática: clínica e prática hospitalar. São Paulo: Santos, 2005.

RODRIGUES, L. C. B. Vivência da sexualidade de idosos(as). 2008. 92 f. Dissertação (Mestrado) Universidade Federal do Rio Grande, Rio Grande, 2008. Disponível em: <https://sistemas.furg.br/ sistemas/sab/arquivos/bdtd/tde_arquivos/9/TDE2009-0 I-30T I I |65 I Z- | 30/Publico/Luiz.pdf > . Acesso em: 09 jan. 2017.

SALGADO, M. A. Velhice: uma nova questão social. São Paulo: Sesc, 2005.

SILVA, R. M. O. de. A sexualidade no envelhecer: um estudo com idosos em reabilitação. Acta Fisiátrica, São Paulo, v. 10, n. 3, p. I07-II2, dez. 2003.

SIQUEIRA, R. L. de; BOTELHO, M. I. V.; COELHO, F. M. G. A velhice: algumas considerações teóricas e conceituais. Ciência e Saúde Coletiva, Rio de Janeiro, v. 7, n. 4, p. 899906, 2002.

TEMPSKI, P. Diálogo filosófico sobre qualidade de vida .... A Philosophical Dialogue on Quality of Life. Revista Brasileira de Educação Médica, Rio de Janeiro, v. I, p. 62, maio 2004.

UCHÔA, E. Contribuições da antropologia para uma abordagem das questões relativas à saúde do idoso. Caderno de Saúde Pública, Rio de Janeiro, v. 19, n. 3 p. 849-853, maio/jun. 2003.

VASCONCELLOS, D. et al. A sexualidade no processo do envelhecimento: novas perspectivas - comparação transcultural. Estudos de Psicologia, Natal, v. 9, n. 3, p. 4I3-4I9, dez. 2004.

VIEIRA, K. F. L. Sexualidade e qualidade de vida do idoso: desafios contemporâneos e repercussões psicossociais. 20I2. 234 f. Tese (Doutorado em Psicologia Social) - Centro de Ciências Humanas, Letras e Artes, Universidade Federal da Paraíba, João Pessoa, 2012. Disponível em: <https://sigaa. ufpb.br/sigaa/public/programa/defesas.jsf?lc $=$ pt_ BR\&id $=\mid 900 \#>$. Acesso em: $\mid 3$ jan. 2017. 